\title{
When More is Better: Impact of Primary Care Office Visits on Severe Obesity
}

Rani N Rao and Jessica Bartfield *

Department of Medicine, Loyola University Medical Center, Maywood, IL, USA

*Corresponding author: Jessica Bartfield, Department of Medicine, Loyola University Health System, Maywood, IL, USA, Tel: 312-498-5175; Fax: 312-498-5175; Email: jbartfield@lumc.edu

Rec date: June 22, 2016; Acc date: Nov 15, 2016; Pub date: Nov 22, 2016

Copyright: (c) 2016 Rao RN, et al. This is an open-access article distributed under the terms of the Creative Commons Attribution License, which permits unrestricted use, distribution, and reproduction in any medium, provided the original author and source are credited.

\begin{abstract}
Background: Among patients with obesity, the subset of patients with severe obesity has been increasing at the fastest rate. Although there is literature which suggests modest effectiveness of weight loss counselling by primary care providers, many primary care clinicians face frustration with the management of obesity. Reasons for this include time constraints, poor reimbursement, and perceived inadequacy or futility of obesity treatments. Despite these obstacles, we hypothesize that primary care clinicians still positively impact weight loss for patients with severe obesity.
\end{abstract}

Methods: We performed a retrospective chart review of patients with severe obesity seen in the primary care clinics of a university health system. The body mass index (BMI) was calculated and tracked for each office visit during the study period of four years. The difference between the initial weight and final weight in the study period was calculated and correlated to visit frequency.

Results: There was a positive correlation between visit frequency and the magnitude of change in BMI.

Conclusions: The positive correlation between visit frequency and change in BMI supports the importance of primary care clinicians in the fight against obesity.

Keywords: Patient; Obesity; Weight loss

\section{Introduction}

It is more common for an American adult to be at an abnormal weight rather than a normal weight, when classified by the body mass index (BMI>25). One out of every three adults struggles with obesity (BMI $>30)$, and the number of adults struggling with severe obesity $(\mathrm{BMI}>40)$ has been increasing at the fastest rate [1]. The complex and multifactorial etiology of obesity poses a challenge to effective treatment, particularly treatment that result in long-term weight loss maintenance.

Primary care clinicians remain at the forefront of obesity detection and treatment initiation. Studies suggest that patients who receive any weight loss counselling from primary care physicians lose more weight [2]. Furthermore, simply the addition of obesity to a patient's problem list has been associated with more frequent weight loss intervention by a primary care provider [3].

Fortunately, recently established obesity guidelines provide useful algorithms to guide primary care physicians through disease screening, assessment of disease severity, readiness for weight loss, and stepwise treatment. They specify a reasonable weight loss goal over the short term and reinforce the need for on-going follow-up for weight loss maintenance [4-6]. For patients with poor weight loss progress or with severe obesity, the guidelines recommend a specific visit frequency for more intensive behavioural modification, roughly 14 "sessions" within 6 months [4]. Unfortunately, many primary care physicians will struggle to execute this last recommendation due to previously cited barriers of time, reimbursement, perceived competency, and futility; often preferring to refer patients to a specialist [7-9].

To better implement treatment, it needs to be determined whether and how the number of primary care visits influences weight change for patients struggling with severe obesity. Finding an improvement in weight change aside from the specifics of obesity management may provide much needed encouragement for primary care providers to provide more frequent contact to high-risk patients.

Furthermore, little data exist regarding long term weight change patterns for patients with morbid obesity in the primary care setting. Other chronic diseases warrant specified physician visit frequency for monitoring, such as diabetes or hypertension (i.e., every four months), to ensure good control of disease and adjusted treatment if uncontrolled. Given the chronic, relapsing nature of obesity, similar practical recommendations are needed. In this context, we investigated the association between the number of primary care visits over four years, and change in BMI for patients with severe obesity.

\section{Methods and Material}

We conducted an IRB approved, retrospective electronic medical record (EMR) chart review of patients seen at the primary care offices of an academic medical center. The EMR data abstractor collected a convenience sample of patients with a body mass index (BMI) equal to or greater than 40 (severe obesity) during the entire year of 2010. For these patients, we studied the changes in BMI over time until December 31, 2014 (Figure 1). 
Citation: $\quad$ Rao RN, Jessica B (2016) When More is Better: Impact of Primary Care Office Visits on Severe Obesity. Gen Med (Los Angeles) 4:

Page 2 of 4

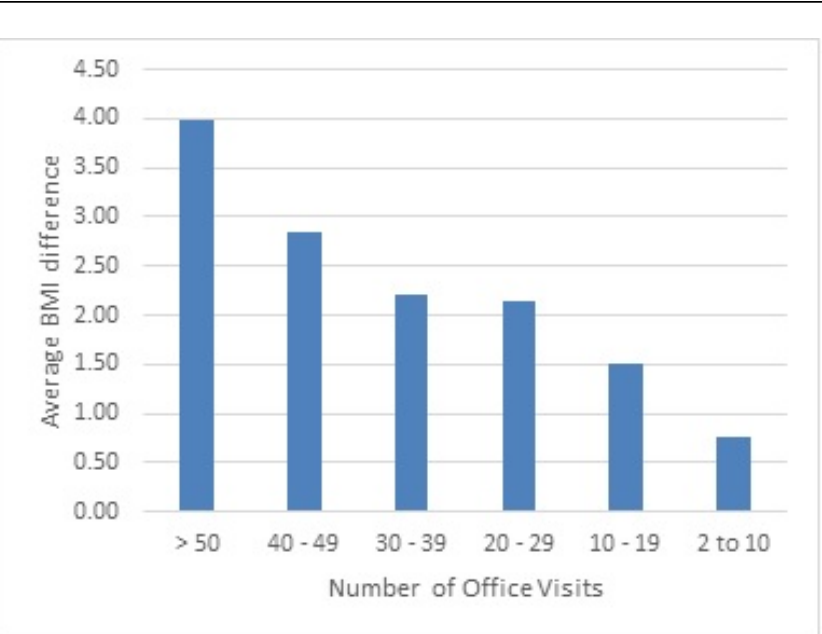

Figure 1: Comparing number of office visits to average change in BMI.
We were given data that were password protected and that deidentified the patients to protect their privacy. Individual charts were not accessed or reviewed. Data were provided in a system approved shared folder which was accessed only by the investigators.

Adults in the age range of 20-65 years were included in the study. We excluded patients at risk for frequent weight changes due to congestive heart failure, kidney disease, liver disease and/or active cancer. Similarly, we excluded patients on anti-obesity pharmacotherapy, antipsychotic medications, steroids, antidepressant medications or those with a history of bariatric surgery.

For all patients who had equal to or greater than two visits, the BMI for each visit was calculated. Change in BMI from the first visit to the last visit was calculated. Number of visits for each patient during the entire study period $(1 / 1 / 2010$ to $12 / 31 / 2014)$ was calculated. We categorized the number of visits during the study period as greater than 50 visits, 40 to 49 visits, 30 to 39 visits, 20 to 29 visits, 10 to 19 visits, and less than 10 visits. We then calculated the average change in BMI between the first and last visits for each category (Table 1).

\begin{tabular}{|l|l|l|l|l|l|l|}
\hline $\begin{array}{l}\text { Number of visits } \\
\mathbf{4 0}\end{array}$ & $\mathbf{3 0 - 3 9}$ & $\mathbf{2 0 - 2 9}$ & $\mathbf{1 0 - 1 9}$ & $<10$ & \\
\hline $\begin{array}{l}\text { Average } \\
\text { Difference }\end{array}$ & 4.96 & 3.29 & 3.26 & 2.72 & 1.62 & \\
\hline Number of patients & 21 & 24 & 56 & 165 & 628 & 894 \\
\hline
\end{tabular}

Table 1: Number of patients and average decrease in BMI points for each category of office visits.

Microsoft Excel spread sheet was used to record all data. All analysis was completed using a significance level of 0.05 .

\section{Results}

The EMR tool identified 894 patients with a BMI greater than 40 in 2010 who also met inclusion criteria.
Each visit category showed a reduction in BMI between the first and last visits (Table 2). The data show a positive correlation of 0.5468 between the number of visits and change in BMI (Figure 2). This correlation has a significance level of $1.3444 \mathrm{E}-08$, implying that the correlation is significant at an alpha of 0.05 . Thus, there is evidence that the correlation between the number of visits and BMI difference is significant.

\begin{tabular}{|l|l|l|l|l|l|l|l|}
\hline \multicolumn{2}{|l|}{ Regression statistics } & & & & & \\
\hline Multiple R & 0.188535987 & & & & & & \\
\hline $\mathrm{R}^{2}$ & 0.035545819 & & & & & & \\
\hline Adjusted R & 0.034464592 & & & & & & \\
\hline Standard Error & 11.77992523 & & & & & & \\
\hline Observations & 894 & & & & & & \\
\hline ANOVA & & & & & & & \\
\hline Regression & 1 & SS & MS & F & Significance F & & \\
\hline Residual & 892 & 123779.8416 & 138.7666385 & & $1.3444 E-08$ & & \\
\hline Total & 893 & 128341.8579 & & & & & \\
\hline
\end{tabular}


Citation: $\quad$ Rao RN, Jessica B (2016) When More is Better: Impact of Primary Care Office Visits on Severe Obesity. Gen Med (Los Angeles) 4:

Page 3 of 4

\begin{tabular}{|l|l|l|l|l|l|l|l|l|}
\hline & Coefficients & Standard Error & $t$ Stat & p-value & Lower 95\% & Upper 95\% & $\begin{array}{l}\text { Lower } \\
95.0 \%\end{array}$ & $\begin{array}{l}\text { Upper } \\
95.0 \%\end{array}$ \\
\hline Intercept & 8.161762335 & 0.439149574 & 18.58538142 & $2.00967 \mathrm{E}-65$ & 7.29987551 & 9.023649161 & 7.29987551 & $\begin{array}{l}9.02364916 \\
1\end{array}$ \\
\hline X Variable 1 & 0.546817026 & 0.095368761 & 5.733712155 & $1.3444 \mathrm{E}-08$ & 0.359643717 & 0.733990335 & $\begin{array}{l}0.35964371 \\
7\end{array}$ & $\begin{array}{l}0.73399033 \\
5\end{array}$ \\
\hline
\end{tabular}

Table 2: ANOVA table for data on number of office visits and change in BMI

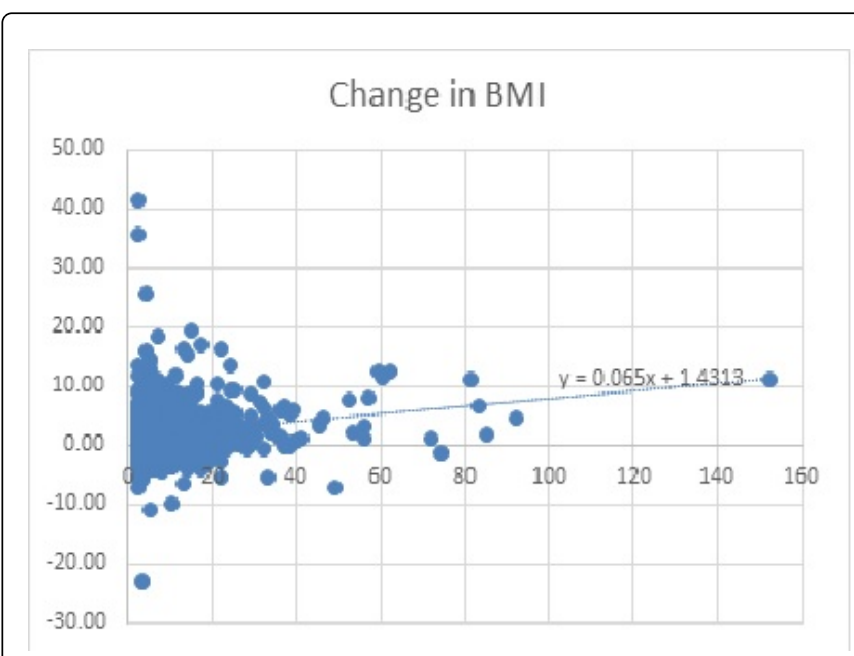

Figure 2: Scatter plot of number of office visits vs. change in BMI.

\section{Discussion}

This single center, retrospective pilot study of over 800 primary care patients with severe obesity found a direct correlation between the number of clinic office visits and changes in BMI over the course of four years. These findings stand out from prior data that focuses on type of counselling delivered, mode of delivery, resources utilized, etc. These specifics may intimidate primary care clinicians who cannot readily translate the findings into clinical practice. Yet with our findings, primary care clinicians, overwhelmed by the burdens of treating patients with severe obesity, can be encouraged that simply offering greater contact to patients with severe obesity improves weight loss. In addition, our findings lend support to the call for improved primary care access, and thus more office visits, for patients with severe obesity as they have shown to be at risk for inferior primary care access and preventive care $[10,11]$. The next reasonable study would tease out how and why patients with severe obesity lose more weight when they have more visits with their primary care clinicians. Potential reasons include superior detection of obesity, more opportunity and time for weight loss counselling, more frequent monitoring of weight changes, or greater health literacy gained from the visits. It also may be that patients that had a greater number of physician visits suffer from more obesity related comorbidities, better motivating both physicians and patients to target and tackle the root cause. Furthermore, a novel finding from further study would be a distinct visit interval that allowed for greater weight loss; this could be suggested in treatment guidelines.
Yet even if the visits were unrelated to obesity or its comorbidities, height, weight and BMI were recorded more often, providing one of the key behaviours for long term weight loss and maintenance- self monitoring [12].

The shift towards obesity as a chronic, relapsing disease that is managed and not cured requires optimized recommendations about long-term follow-up. Unfortunately, the majority of weight loss studies, particularly for behavioural modifications, span a mere 6-12 months. Furthermore, these behavioural modification programs differ vastly in design, and thus the frequency and total number of visits during a specified time frame varies. This prevents good generalizability and implementation by primary care clinicians.

This study offers much needed long-term data and a clear, simple message- patients with severe obesity who have a greater number of primary care clinician visits lose more weight (measured by change in BMI). Determining the how and the why will further advance care of patients with severe obesity in the primary care setting.

\section{References}

1. Ogden CL, Carroll MD, kit BK, Flegal KM (2014) Prevalence of childhood and adult obesity in the United States, 2011-2012. JAMA 311:806-814.

2. Rose SA, Poynter PS, Anderson JW, Noar SM, Conigliaro J (2013) Physician weight loss advice and patient weight loss behavior change: a literature review and meta-analysis of survey data. Int J Obes(Lond) 37:118-28.

3. Banerjee ES, Gamber A, Folgeman C (2013) Adding obesity to the problem list increases the rate of providers addressing obesity. Fam Med 45:629-633.

4. Jensen MD, Ryan DH, Apovian CM, Ard JD, Comuzzie AG, et al.(2013) AHA/ACC/TOS guideline for the management of overweight and obesity in adults: a report of the American College of Cardiology/American Heart Association task force on practice guidelines and the Obesity Society. Circulation 129:S102-138.

5. Bray GA, Fruhbeck G, Ryan DH, Wilding JPH (2016) Management of obesity. Lancet 387:19747-19756.

6. LeBlanc E, O'Connor E, Whitlock EP, Patnode C, KapkaT (2011) Screening for and management of obesity and overweight in adults. Agency for Healthcare Research and Quality, Publication 11-05159-EF-1.

7. Gunther S, Guo F, Sinfield P, Rogers S, Baker R (2012) Qual Prim. Care 20:93-103.

8. Blackburn M, Stathi A, Keogh E, Eccleston C (2015) Raising the topic of weight in general practice: perspectives of GPs and primary care nurses. BMJ Open 5:e008546.

9. Bennett WL, Gudzune KA, Appel LJ, Clark JM (2014) Insights from the POWER practice-based weight loss trial: a focus group study on the PCPs role in weight management. J Gen Intern Med 29:50-58.

10. Gaglioti AH, Petterson S, Bazemore A, Philips R (2016) Access to primary care in US counties is associated with lower obesity rates. JABFM 29:182-190. 
Citation: $\quad$ Rao RN, Jessica B (2016) When More is Better: Impact of Primary Care Office Visits on Severe Obesity. Gen Med (Los Angeles) 4: 279. doi:10.4172/2327-5146.1000279

Page 4 of 4

11. Wee CC, McCarthy EP, Davis RB, Phillips RS (2000) Screening for cervical and breast cancer: Is obesity an unrecognized barrier to preventive care? Ann Intern Med 132:697-704.
12. Wing RR, Phelan S (2005) Long-term weight loss maintenance. Am J Clin Nutr 82:222S-2225S 